\title{
Nailing of diaphyseal ulna fractures in adults-biomechanical evaluation of a novel implant in comparison with locked plating
}

Johannes Christof Hopf ${ }^{1,2^{*}}$ D, Dorothea Mehler ${ }^{1}$, Tobias Eckhard Nowak ${ }^{1}$, Dominik Gruszka', Daniel Wagner ${ }^{1}$ and Pol Maria Rommens

\begin{abstract}
Background: Adult forearm fractures require surgical treatment in most cases. Open reduction and internal fixation with plate osteosynthesis is the therapy of choice. Intramedullary fixation offers several advantages compared to plate fixation but is not routinely used. The aim of our study was to compare a newly designed ulna nail with angular stable plating in a biomechanical testing setup of an ulna shaft fracture with a diaphyseal defect.

Methods: Ten pairs of sawbones with a defect osteotomy of the ulna shaft (OTA 2U2C3) were fixed with an interlocked nail or locked plate osteosynthesis. The constructs were tested under four-point bending, torsional loading and axial loading in a servo-pneumatic testing machine to compare the stiffness of both stabilization methods.
\end{abstract}

Results: The nail constructs show lower yet sufficient bending stiffness $(62.25 \pm 6.64 \mathrm{~N} / \mathrm{mm})$ compared to the plate constructs $(71.2 \pm 5.98 \mathrm{~N} / \mathrm{mm}, p=0.005)$. The torsional loading test shows superior stiffness of the plate constructs $(0.24 \pm 0.03 \mathrm{Nm} /$ deg vs. $0.1 \pm 0.01 \mathrm{Nm} /$ deg; $p<0.001)$, while the axial loading shows superior stiffness of the nail constructs (1028.9 $\pm 402.1 \mathrm{~N} / \mathrm{mm}$ vs. $343.9 \pm 112.6 \mathrm{~N} / \mathrm{mm} ; p<0.001)$.

Conclusions: Intramedullary nailing of ulna shaft fractures obtains sufficient but lower stability in bending and torsional loading when compared to rigid angular stable plating and could be an alternative technique to plate fixation. The lower stability and the closed stabilization technique allow for a rapid periosteal healing, which is not present in stiffer constructs.

Keywords: Nailing, Ulna shaft, Biomechanical study

\footnotetext{
*Correspondence: joh.hopf@gmail.com

1 Department of Orthopedics and Trauma Surgery, University Medical Center, Langenbeckstraße 1, 55131 Mainz, Germany

${ }^{2}$ Mainz, Germany
}

(c) The Author(s). 2020 Open Access This article is licensed under a Creative Commons Attribution 4.0 International License, which permits use, sharing, adaptation, distribution and reproduction in any medium or format, as long as you give appropriate credit to the original author(s) and the source, provide a link to the Creative Commons licence, and indicate if changes were made. The images or other third party material in this article are included in the article's Creative Commons licence, unless indicated otherwise in a credit line to the material. If material is not included in the article's Creative Commons licence and your intended use is not permitted by statutory regulation or exceeds the permitted use, you will need to obtain permission directly from the copyright holder. To view a copy of this licence, visit http://creativecommons.org/licenses/by/4.0/ The Creative Commons Public Domain Dedication waiver (http://creativecommons.org/publicdomain/zero/1.0/) applies to the data made available in this article, unless otherwise stated in a credit line to the data. 


\section{Introduction}

In adult diaphyseal forearm fractures, precise restoration of the anatomy is crucial to achieve bony union and good functional results. Therefore, most adult diaphyseal forearm fractures require surgical treatment [1]. Several surgical methods have been described for their treatment including plate-screw osteosynthesis and intramedullary nailing [2]. Open reduction and plate osteosynthesis of forearm fractures is an accepted treatment option and showed good functional results since many years [3]. Comminuted or segmental forearm fractures increase the risk for infection and non-union when treated with open reduction and plate osteosynthesis. Intramedullary fixation is less often used in adult forearm fractures, although they offer several advantages compared to plate fixation as less periosteal stripping, preservation of the fracture hematoma, and biomechanical advantages of a central load-bearing implant [1, 4-6]. This could be explained with a challenging implantation process with difficulties in restoration of forearm geometry. Also, the risk of neurovascular injuries by malpositioned locking screws can lead to severe complications.

Comparable functional outcomes of nail and plate fixation were described in several clinical studies [7-9]. Nailing of the ulna combined with plating of the radius is described as an acceptable hybrid fixation method for both-bone forearm fractures [10]. A combined biomechanical and clinical study comparing plating and nailing techniques in adult forearm fractures favored the combination of ulna nailing and radius plating because of better functional outcomes, fewer complications, and good biomechanical results compared to other osteosynthetic techniques (both-bone nailing, both-bone plating, ulna plating, and radius nailing) [11].

Biomechanical principles established by the AO/ASIF (Arbeitsgemeinschaft für Osteosynthesefragen/Association for the Study of Internal Fixation) postulated that a certain amount of strain by a load-sharing implant like an intramedullary nail is favorable for periosteal bony healing with callus. This principle especially applies in comminuted fractures and is used successfully in other long bone fractures [12].

The aim of our study was to compare the biomechanical characteristics of a newly designed, anatomically shaped ulna nail with angular stable plating in a biomechanical test setup of an unstable ulna shaft fracture.

\section{Materials and methods}

This study is a biomechanical comparison of a newly developed ulna nail and a standard angular stable plate in an ulna shaft fracture model using sawbones. We performed a four-point bending, a torsional loading, and an axial loading test.

\section{Bones and fracture type}

We used ten pairs of large left 4th generation composite sawbones (\#3426, Sawbones ${ }^{\circledR}$ Pacific Research Laboratories, Vashon Island, USA) for the biomechanical testing. We simulated a segmental ulna shaft fracture (OTA 2U2C3 (Orthopaedic Trauma Association)) with high grade of instability by creating a standardized shaft osteotomy with a 10-mm gap.

\section{Implants}

The newly developed ulna nail was developed in a cooperation agreement between the authors and MEDIN a.s. (Nove Mesto na Morave, Czech Republic). Prior to the determination of the characteristics of the new nail, a CT-graphic study of the ulna shaft was performed. The feasibility of implantation of the newly designed nail was checked in cadaveric tests. We used ten nails made of forged titanium (Ti-6Al-4 V ELI) with a diameter of 6 $\mathrm{mm}$ in the proximal part and $5 \mathrm{~mm}$ in the mid-shaft and distal part. The length of the nail was $230 \mathrm{~mm}$ with a radial bending within the proximal $120 \mathrm{~mm}$ with a radius of $735 \mathrm{~mm}$ ( $9^{\circ}$ radial bending). The nail offers two retrograde locking options in the proximal part placed towards the tip of the olecranon and three metaphyseal locking options placed into the coronoid process. The locking is done with $2.7 \mathrm{~mm}$ locking screws with threaded heads for stable fixation in the first cortex. All proximal and metaphyseal locking screws are inserted through a targeting device. The angulation of the metaphyseal screws prevents an intraarticular screw positioning into the proximal radio-ulnar joint. The distal locking is done free-hand, ideally with a radiolucent drive in anterior-posterior direction. The nail offers one locking hole and notches proximal to the hole for easier locking. Figure 1 shows an X-ray in anterior-posterior view and lateral view of the nail with inserted locking screws and after potting in polymethylmethacrylate cement. For the second group, ten angular stable $3.0 \mathrm{~mm}$ plates with a length of $84 \mathrm{~mm}$ (7 holes) were used.

\section{Implantation process}

The nails were implanted in a standardized technique with prior reaming of the intramedullary canal with hand reamers. The canal was reamed up to $7 \mathrm{~mm}$ in the proximal part and $6 \mathrm{~mm}$ in the distal part to allow easy insertion of the nail. All proximal and metaphyseal locking options were used in the nail. The distal locking was done under image intensifier with three screws, one through the hole and two into the notches. The plates were fixated with three $3.5 \mathrm{~mm}$ locking screws proximal and distal to the osteotomy (6 cortices on each side) on the dorso-ulnar side of the ulna. Figure 2 shows both constructs after the implantation process. All constructs 


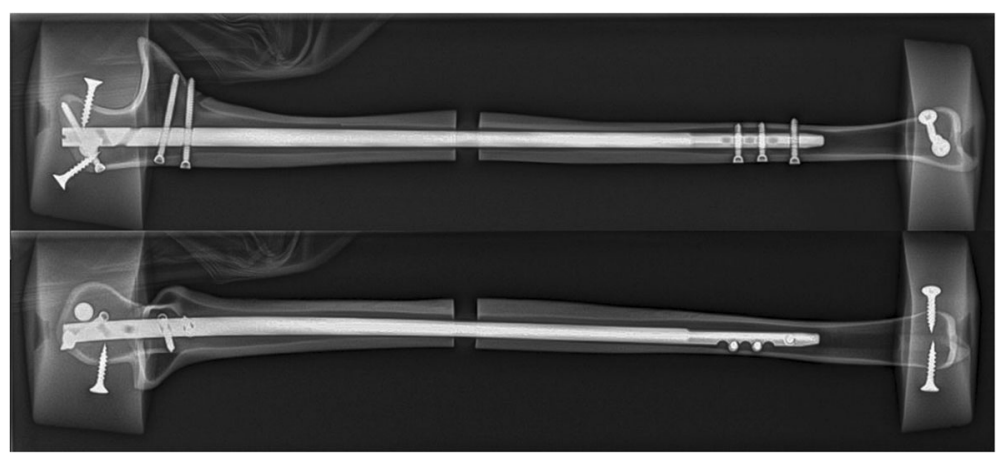

Fig. 1 X-ray in anterior-posterior and lateral view of a left nail with inserted locking screws after potting in PMMA cement

underwent X-rays in two planes to verify correct implant and screw positions.

\section{Testing setup}

A servo-pneumatic testing machine (SincoTEC, ClausthalZellerfeld, Germany) was used for the biomechanical tests. The constructs were loaded to accomplish a linear elastic deformation; testing of load-to-failure was not intended. We measured the stiffness values with an established method using the applied forces and torques and the resulting movements [13].

For the four-point bending test, the constructs were placed in the testing machine with a preload of $10 \mathrm{~N}$. Then, a bending moment of $7.5 \mathrm{Nm}$ was applied to the samples in an anterior-posterior direction. Six load changes were performed with a frequency of $0.1 \mathrm{~Hz}$. For measurement of the bending stiffness, the last three load changes were used. Figure 3 shows the four-point bending testing setup with clamped nail construct.

After the four-point bending test, the constructs were potted in polymethylmethacrylate cement (PMMA) with added screws to secure the fixation and fixed in the testing machine at both ends. The torsional loading was done torque-controlled with a torque of $2 \mathrm{Nm}$. Six load changes were performed with a frequency of $0.05 \mathrm{~Hz}$. Again, three pre-cycles and three measurement cycles were performed to determine torsional stiffness.
Finally all constructs were loaded under axial compression with a force of $250 \mathrm{~N}$ and a preload of $10 \mathrm{~N}$. Six load changes with a frequency of $0.1 \mathrm{~Hz}$ were performed. The last three load changes were used for the measurement of the axial stiffness.

The analysis of the four-point bending and axial loading was done using the force-displacement-diagram. The torsional stiffness was determined from the values of the torque-angle-diagram. Figure 4 shows the test setup for the torsional and axial loading.

\section{Data analysis and statistics}

With an alpha level set at 0.05, the sample size of ten pairs of sawbones was calculated for a power $(1-\beta)$ of 0.8 and an effect size of 1.4. For the statistical test, a Mann-Whitney Rank Sum test for independent samples was used with the statistical software SigmaStat (Systat Software GmbH, Erkrath, Germany).

\section{Results}

No implant failure occurred in any construct. We detected no macroscopic implant loosening in both groups after test completion. Table 1 shows the results of the four-point bending, torsional loading, and axial loading tests. All constructs showed a linear elastic behavior in our testing setup; no plastic deformation occurred.

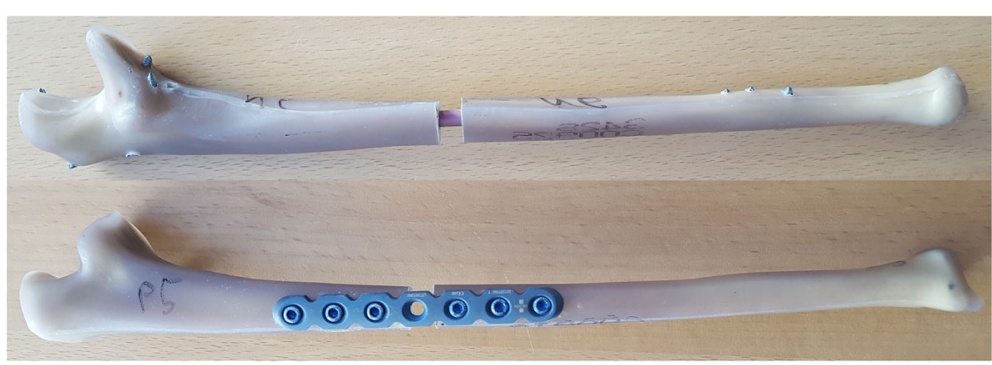

Fig. 2 Nail und plate construct after osteosynthesis in lateral view 


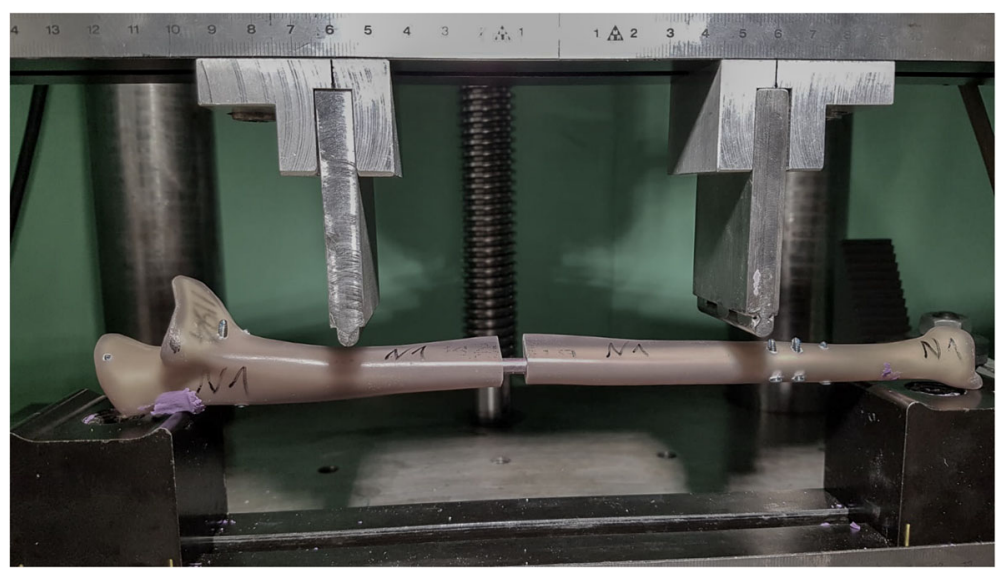

Fig. 3 Four-point bending test setup with mounted nail construct

\section{Four-point bending}

The plate constructs showed a higher bending stiffness $(71.2 \pm 5.98 \mathrm{~N} / \mathrm{mm})$ compared to the nail constructs $(62.25 \pm 6.64 \mathrm{~N} / \mathrm{mm})$ in anterior-posterior direction $(p=$ 0.005). The average bending stiffness of the nail constructs amounts approximately $87 \%$ of the plate constructs. Figure 5 shows the force-displacement-diagram of pair 4 of the constructs for four-point bending.

\section{Torsional loading}

The plate constructs showed higher torsional stiffness $(0.24 \pm 0.03 \mathrm{Nm} / \mathrm{deg})$ compared to the nail constructs $(0.1 \pm 0.01 \mathrm{Nm} / \mathrm{deg} ; p<0.001)$. The torsional stiffness of the nail constructs amounts approximately $42 \%$ of the plate constructs.

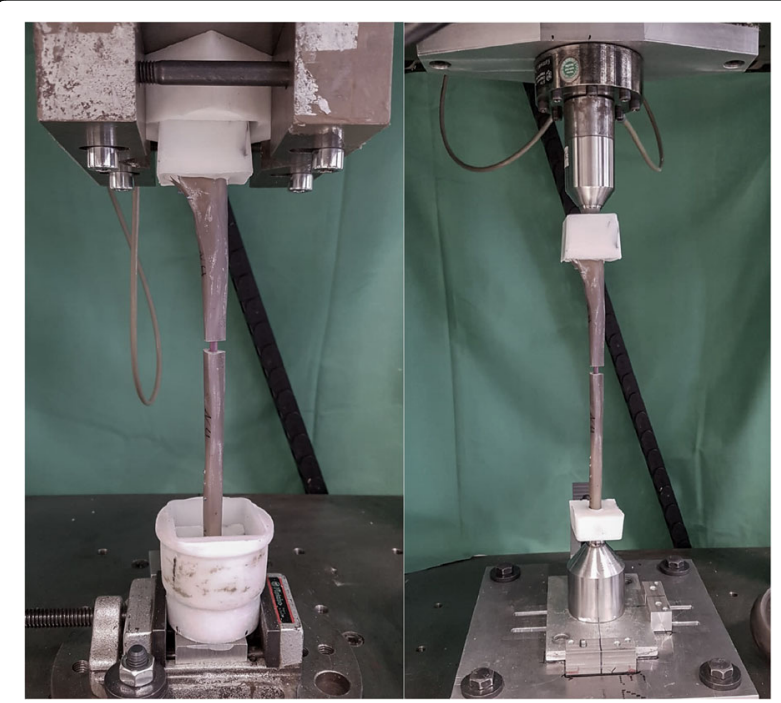

Fig. 4 Test setups for the torsional and axial loading with mounted nail construct

\section{Axial loading}

For the testing under axial loading, intramedullary implants have a concept-related advantage compared to extramedullary implants. The nail constructs had a significantly higher axial stiffness $(1028.9 \pm 402.1 \mathrm{~N} / \mathrm{mm})$ compared to the plate constructs $(343.9 \pm 112.6 \mathrm{~N} / \mathrm{mm} ; p<$ 0.001). The axial stiffness of the plate constructs amounts about one third compared to the nail constructs.

\section{Discussion}

Since 1958, the basic AO principles for fracture treatment are worldwide accepted [14]. Rigid fixation under fracture compression leads to primary bone healing without callus formation. The fixation of comminuted fractures usually does not allow anatomic reduction and compression across the fracture. These fractures have the best chances of bony union with an osteosynthetic fixation, which allows a certain amount of strain using more working length [15]. Our results show significant higher bending and torsional stiffness of the plate constructs. Load-sharing devices like bridge plates or intramedullary nails allow a controlled amount of strain, which stimulates callus formation and secondary bone healing [1].

Intramedullary fixation of ulna fractures is a wellestablished technique in children [16]. For adolescents, the clinical results of intramedullary forearm fixation are

Table 1 Results of the four-point bending, torsional loading, and axial loading tests and $p$ value after Mann-Whitney Rank Sum test

\begin{tabular}{llll}
\hline Parameters & Nail & Plate & $\boldsymbol{p}$ value \\
\hline Four-point bending $[\mathrm{Nm} / \mathrm{deg}]$ & $62.25 \pm 6.64$ & $71.2 \pm 5.98$ & $p=0.005$ \\
Torsional loading $[\mathrm{Nm} / \mathrm{deg}]$ & $0.1 \pm 0.01$ & $0.24 \pm 0.03$ & $p<0.001$ \\
Axial loading $[\mathrm{N} / \mathrm{mm}]$ & $1028.9 \pm 402.1$ & $343.9 \pm 112.6$ & $p<0.001$ \\
\hline
\end{tabular}




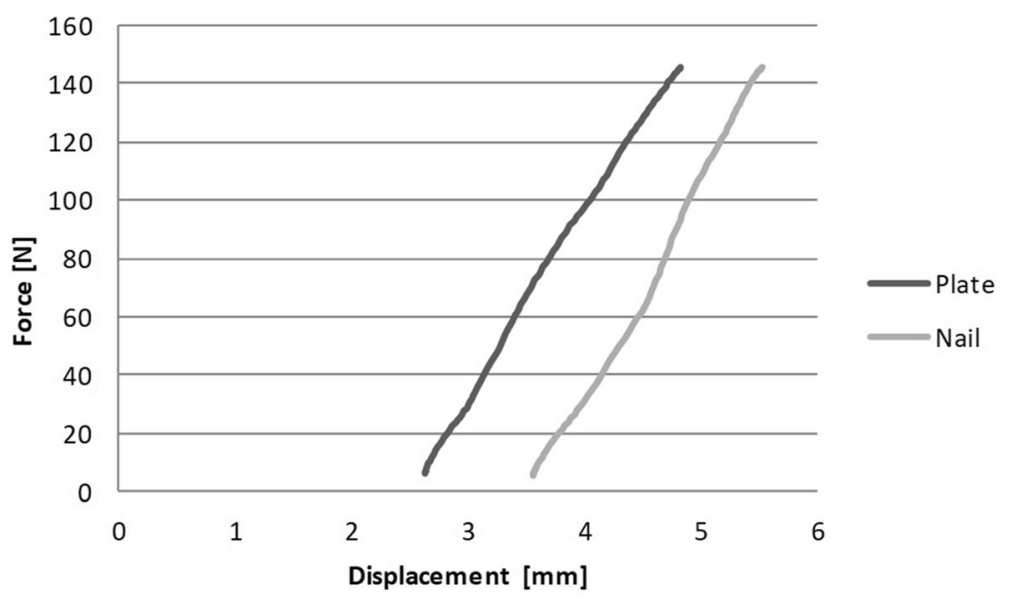

Fig. 5 Force-displacement-diagram of pair four of the constructs

varying. In comparison to elastic stable intramedullary nailing, good clinical results could be published for locked intramedullary implants [17]. Some authors described an increased complication rate for intramedullary techniques compared to the pediatric population $[18,19]$. Especially the risk of non-union increases with increasing age due to insufficient stability of unlocked intramedullary implants $[20,21]$. The development and use of locked intramedullary implants showed promising clinical results in the non-pediatric population with diaphyseal forearm fractures in several studies [22-25].

Intramedullary locked nailing offers fracture stabilization with an intended amount of strain combined with other relevant advantages of a closed surgical technique like preservation of the fracture hematoma and less impairment of the periosteal blood supply at the fracture site. We postulate that the characteristics of the newly designed long ulna nail are advantageous for uneventful bone healing, despite the lower stability in bending and rotation. With this biomechanical study, we surely cannot proove this hypothesis, and further clinical studies are necessary for evaluation. Until today, indications for ulna nailing are often restricted to special cases like pathologic fractures or revision surgery [26, 27]. Historically, especially drawbacks like immature implants and techniques, which resulted in insufficient stability and a high complication rate, prevented an enforcement of intramedullary nailing of ulna fractures [28]. With further development of the implants and techniques, like the introduction of locked implants, the clinical results improved, and fracture union could be achieved in a vast majority of cases [29-31].

Jones et al. described a biomechanical comparison of plate fixation and unlocked intramedullary rods in 1995 [32]. The torsional stiffness of the nail constructs $(2.23 \%$ of intact forearm) were significantly lower compared to the plate constructs $(83.4 \%$ of intact forearm) in this study [32]. In a recent biomechanical study, both-bone forearm nailing showed slightly lower stability compared to both-bone plate fixation [11]. The combination of ulna nailing and radius plating showed good biomechanical stability with the lowest complication rate and best clinical outcome in a clinical examination [11]. For the mentioned hybrid fixation of adult forearm fractures, Lee et al. showed good clinical results as well [33]. We expected higher torsional stiffness of the plate constructs in our study because of the lower distance of the locking screws to the osteotomy gap. Due to the primary bone healing without callus formation and due to periosteal damage by the plate, a relevant risk of refracture after plate removal is described [34]. We do not expect the same rate of refractures after nailing like shown for clavicle fractures $[30,35]$. Despite the mentioned improvements of the implants and good biomechanical and clinical results, locked ulna nailing is not a frequently used treatment option. Our newly developed nail offers an anatomically preshaped design and several locking options with the possibility of angular stable screw fixation in the first cortex. We hypothesize to extend the indications for locked ulna nailing with this novel implant in particular for comminuted and segmental fracture of the ulna shaft.

Limitations of our study include the use of artificial bones instead of cadaveric bones and the fact that it is a biomechanical test, which can only approximate physiological conditions. Fresh-frozen cadaveric bones are closer to in vivo conditions in most of their biomechanical characteristics. On the other hand, differences in bony density or bone geometry of cadaveric bones can be a restriction as well [36]. Also, comparable biomechanical characteristics of composite bones compared to cadaveric bones with less variability in bone quality are described [37]. Because of the mentioned limitations and the fact that biomechanical studies cannot reproduce the behavior of soft tissues and physiological bone healing 
conditions, our results have to be interpreted carefully and cannot be transferred uncritical into the clinical setting.

In summary, our biomechanical study shows lower stability of the newly developed ulnar nail in bending and torsion than compared to angular stable plate osteosynthesis. The higher elasticity of the construct allows a certain amount of strain at the fracture site. Moreover, fracture hematoma and periosteal blood supply are preserved, which support callus formation and bony healing. These theoretical considerations must be evaluated in further clinical examinations to verify advantages and disadvantages of the new implant and its surgical technique in clinical practice.

\section{Conclusion}

In this biomechanical study, we compared a newly designed intramedullary nail and an angular stable plate in an ulnar defect fracture under bending, torsional, and axial load. Our results show superior biomechanical stability under four-point bending and torsional loading in the plate group. In consideration of the strain theory for diaphyseal fracture healing, the elasticity of the nail construct may promote secondary bone healing. This hypothesis must be proved by clinical examinations. We conclude that this technique could be an alternative method for the treatment of unstable ulna fractures.

\section{Abbreviations \\ OTA: Orthopaedic Trauma Association; AO: Arbeitsgemeinschaft für Osteosynthesefragen; ASIF: Association for the Study of Internal Fixation}

\section{Acknowledgements}

Not applicable.

\section{Authors' contributions}

All authors have made substantial contributions to the following points: (1) Conception and design of the study, or acquisition of data, or analysis and interpretation of data (2) Drafting the article or revising it critically for important intellectual content (3) Final approval of the version to be submitted. All authors contributed to the study conception and design. Material preparation, data collection, and analysis were performed by Hopf JC, Mehler D, and Rommens PM. The first draft of the manuscript was written by Hopf JC, and all authors commented on previous versions of the manuscript. All authors participated in the research and preparation of the manuscript. Statistical analysis was done by Westphal $R$. The manuscript was not previously published and is not under consideration elsewhere. Each author believes that the manuscript represents honest work. The author(s) read and approved the final manuscript.

\section{Funding}

The company MEDIN a.s. provided the implants (plates and nails) for the study.

\section{Availability of data and materials}

The datasets used and/or analyzed during the current study are available from the corresponding author on reasonable request.

\section{Ethics approval and consent to participate}

Not applicable.

\section{Consent for publication}

Not applicable.

\section{Competing interests}

No financial biases exist for any author. On behalf of all authors, the corresponding author states that there is no conflict of interest.

Received: 9 February 2020 Accepted: 27 March 2020

Published online: 20 April 2020

\section{References}

1. Schulte LM, Meals CG, Neviaser RJ. Management of adult diaphyseal bothbone forearm fractures. J Am Acad Orthop Surg. 2014;22:437-46.

2. Bartoníček J, Kozánek M, Jupiter JB. History of operative treatment of forearm diaphyseal fractures. J Hand Surg Am. 2014;39:335-42.

3. Anderson LD, Sisk D, Tooms RE, Park WI. Compression-plate fixation in acute diaphyseal fractures of the radius and ulna. J Bone Joint Surg Am. 1975;57: 287-97.

4. Hierholzer C, Friederichs J, Augat P, Woltmann A, Trapp O, Bühren V, et al. Evolution and principles of intramedullary locked nailing. Unfallchirurg. 2018;121:239-55.

5. Kyle RF. Biomechanics of intramedullary fracture fixation. Orthopedics. 1985; 8:1356-9.

6. He H-Y, Zhang J-Z, Wang X-W, Liu Z. Acumed intramedullary nail for the treatment of adult diaphyseal both-bone forearm fractures. Zhongguo Gu Shang. 2018;31:803-7.

7. Jones DB, Kakar S. Adult diaphyseal forearm fractures: intramedullary nail versus plate fixation. J Hand Surg Am. 2011;36:1216-9.

8. Lee SK, Kim KJ, Lee JW, Choy WS. Plate osteosynthesis versus intramedullary nailing for both forearm bones fractures. Eur J Orthop Surg Traumatol. 2014; 24:769-76.

9. Zhao L, Wang B, Bai X, Liu Z, Gao H, Li Y. Plate fixation versus intramedullary nailing for both-bone forearm fractures: a meta-analysis of randomized controlled trials and cohort studies. World J Surg. 2017;41:722-33.

10. Behnke NMK, Redjal HR, Nguyen VT, Zinar DM. Internal fixation of diaphyseal fractures of the forearm: a retrospective comparison of hybrid fixation versus dual plating. J Orthop Trauma. 2012;26:611-6.

11. Zhang XF, Huang JW, Mao HX, Chen WB, Luo Y. Adult diaphyseal bothbone forearm fractures: a clinical and biomechanical comparison of four different fixations. Orthop Traumatol Surg Res. 2016;102:319-25.

12. Perren SM. Evolution of the internal fixation of long bone fractures. The scientific basis of biological internal fixation: choosing a new balance between stability and biology. J Bone Joint Surg Br. 2002;84:1093-110.

13. Tencer AF, Johnson KD, Kyle RF, Fu FH. Biomechanics of fractures and fracture fixation. Instr Course Lect. 1993;42:19-55.

14. Matter P. History of the $A O$ and its global effect on operative fracture treatment. Clin Orthop Relat Res. 1998:11-8.

15. MacLeod AR, Pankaj P. Pre-operative planning for fracture fixation using locking plates: device configuration and other considerations. Injury. 2018; 49(Suppl 1):S12-8

16. Patel A, Li L, Anand A. Systematic review: functional outcomes and complications of intramedullary nailing versus plate fixation for both-bone diaphyseal forearm fractures in children. Injury. 2014;45:1135-43.

17. Özcan Ç, Taylan Öz T, Türkmen İ. Radius and ulna locking intramedullary nails are safe and reliable after adolescent forearm fractures: a casecontrolled study in adolescents. J Pediatr Orthop B. 2020;29:164-71.

18. Freese KP, Faulk LW, Palmer C, Baschal RM, Sibbel SE. A comparison of fixation methods in adolescent patients with diaphyseal forearm fractures. Injury. 2018:49:2053-7.

19. Truntzer J, Vopat ML, Kane PM, Christino MA, Katarincic J, Vopat BG. Forearm diaphyseal fractures in the adolescent population: treatment and management. Eur J Orthop Surg Traumatol. 2015;25:201-9.

20. Martus JE, Preston RK, Schoenecker JG, Lovejoy SA, Green NE, Mencio GA. Complications and outcomes of diaphyseal forearm fracture intramedullary nailing: a comparison of pediatric and adolescent age groups. J Pediatr Orthop. 2013;33:598-607.

21. Morrison MJ, Speirs JN, Chicorelli AM, Garner M, Flynn JJM, Herman MJ. Intramedullary fixation of both bone forearm fractures in children and adolescents: healing correlates with development of the olecranon apophysis. J Pediatr Orthop. 2019.

22. Gao H, Luo C-F, Zhang C-Q, Shi H-P, Fan C-Y, Zen B-F. Internal fixation of diaphyseal fractures of the forearm by interlocking intramedullary nail: short-term results in eighteen patients. J Orthop Trauma. 2005;19:384-91. 
23. Köse A, Aydın A, Ezirmik N, Can CE, Topal M, Tipi T. Alternative treatment of forearm double fractures: new design intramedullary nail. Arch Orthop Trauma Surg. 2014;134:1387-96.

24. Lee YH, Lee SK, Chung MS, Baek GH, Gong HS, Kim KH. Interlocking contoured intramedullary nail fixation for selected diaphyseal fractures of the forearm in adults. J Bone Joint Surg Am. 2008;90:1891-8.

25. Saka G, Saglam N, Kurtulmuş T, Avcı CC, Akpinar F, Kovaci H, et al. New interlocking intramedullary radius and ulna nails for treating forearm diaphyseal fractures in adults: a retrospective study. Injury. 2014;45(Suppl 1): S16-23.

26. Hofmann A, Hessmann MH, Rudig L, Küchle R, Rommens PM. Intramedullary osteosynthesis of the ulna in revision surgery. Unfallchirurg. 2004;107:58392.

27. Rehman S, Sokunbi G. Intramedullary fixation of forearm fractures. Hand Clin. 2010;26:391-401 vii.

28. Sage FP, Smith H. Medullary fixation of forearm fractures. J Bone Joint Surg Am. 1957:39-A:91-8.

29. Street DM. Intramedullary forearm nailing. Clin Orthop Relat Res. 1986:21930.

30. Weckbach A, Blattert TR, Weisser C. Interlocking nailing of forearm fractures. Arch Orthop Trauma Surg. 2006;126:309-15.

31. Azboy I, Demirtaş A, Alemdar C, Gem M, Uzel K, Arslan H. A newly designed intramedullary nail for the treatment of diaphyseal forearm fractures in adults. Indian J Orthop. 2017;51:697-703.

32. Jones DJ, Henley MB, Schemitsch EH, Tencer AF. A biomechanical comparison of two methods of fixation of fractures of the forearm. J Orthop Trauma. 1995;9:198-206.

33. Lee SK, Kim YH, Kim SM, Choy WS. A comparative study of three different surgical methods for both-forearm-bone fractures in adults. Acta Orthop Belg. 2019;85:305-16.

34. Yao C-K, Lin K-C, Tarng Y-W, Chang W-N, Renn J-H. Removal of forearm plate leads to a high risk of refracture: decision regarding implant removal after fixation of the forearm and analysis of risk factors of refracture. Arch Orthop Trauma Surg. 2014;134:1691-7.

35. Houwert RM, Smeeing DPJ, Ahmed Ali U, Hietbrink F, Kruyt MC, van der Meijden OA. Plate fixation or intramedullary fixation for midshaft clavicle fractures: a systematic review and meta-analysis of randomized controlled trials and observational studies. J Shoulder Elbow Surg. 2016;25:1195-203.

36. Zdero R, Olsen M, Bougherara H, Schemitsch EH. Cancellous bone screw purchase: a comparison of synthetic femurs, human femurs, and finite element analysis. Proc Inst Mech Eng H. 2008;222:1175-83.

37. Cristofolini L, Viceconti M, Cappello A, Toni A. Mechanical validation of whole bone composite femur models. J Biomech. 1996;29:525-35

\section{Publisher's Note}

Springer Nature remains neutral with regard to jurisdictional claims in published maps and institutional affiliations.

Ready to submit your research? Choose BMC and benefit from:

- fast, convenient online submission

- thorough peer review by experienced researchers in your field

- rapid publication on acceptance

- support for research data, including large and complex data types

- gold Open Access which fosters wider collaboration and increased citations

- maximum visibility for your research: over $100 \mathrm{M}$ website views per year

At $\mathrm{BMC}$, research is always in progress.

Learn more biomedcentral.com/submissions 